Provided for non-commercial research and education use. Not for reproduction, distribution or commercial use.

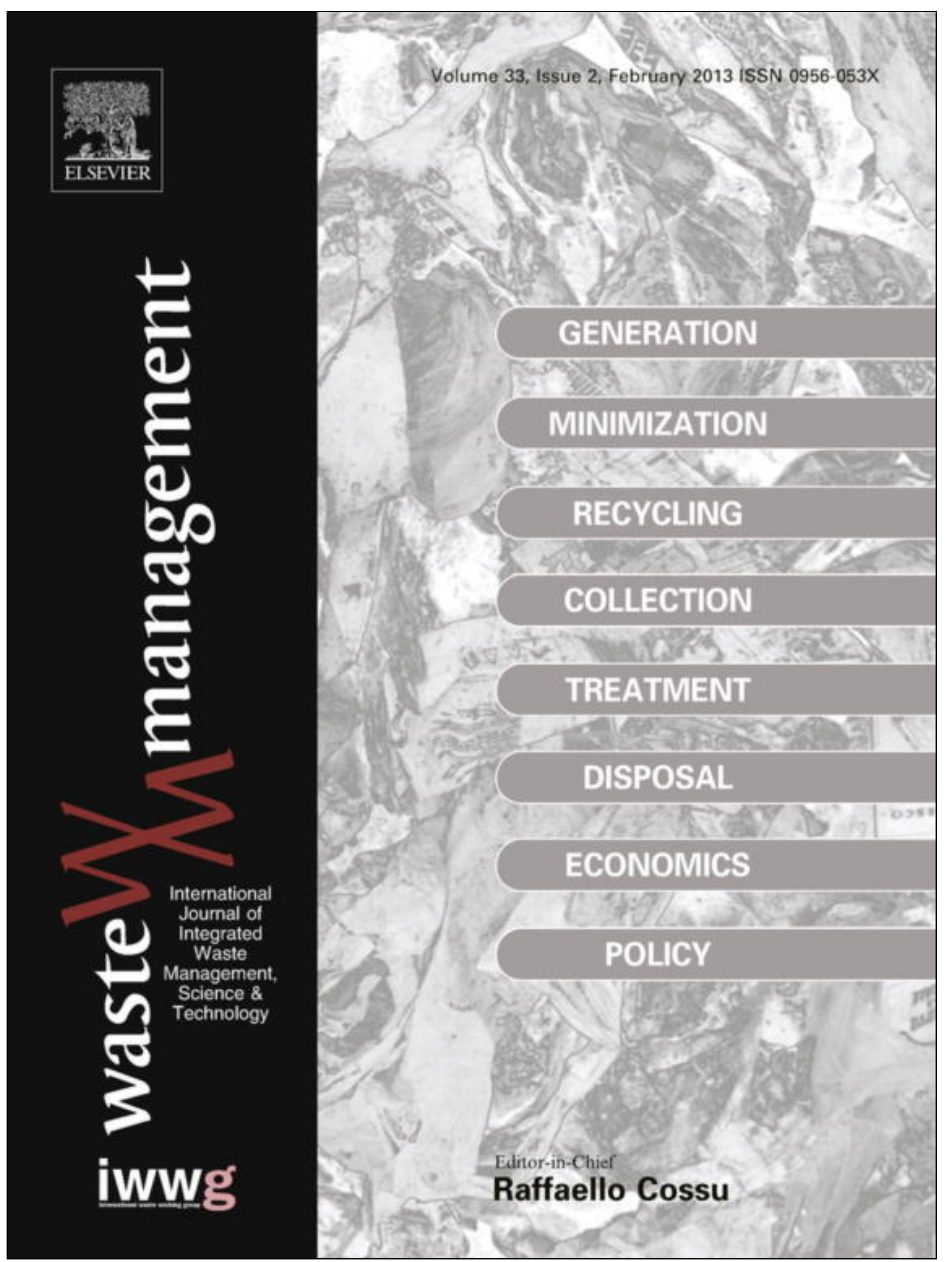

This article appeared in a journal published by Elsevier. The attached copy is furnished to the author for internal non-commercial research and education use, including for instruction at the authors institution and sharing with colleagues.

Other uses, including reproduction and distribution, or selling or licensing copies, or posting to personal, institutional or third party websites are prohibited.

In most cases authors are permitted to post their version of the article (e.g. in Word or Tex form) to their personal website or institutional repository. Authors requiring further information regarding Elsevier's archiving and manuscript policies are encouraged to visit:

http://www.elsevier.com/copyright 


\title{
Mechanisms contributing to the thermal analysis of waste incineration bottom ash and quantification of different carbon species
}

\author{
Stefania Rocca ${ }^{\mathrm{a}}$, André van Zomeren ${ }^{\mathrm{b}, *}$, Giulia Costa ${ }^{\mathrm{a}}$, Joris J. Dijkstra ${ }^{\mathrm{b}}$, Rob N.J. Comans ${ }^{\mathrm{b}, \mathrm{c}}$, \\ Francesco Lombardi ${ }^{\mathrm{a}}$ \\ a University of Rome “Tor Vergata”, Department of Civil Engineering and Computer Science Engineering, Via del Politecnico 1, 00133 Rome, Italy \\ ${ }^{\mathrm{b}}$ Energy Research Centre of the Netherlands (ECN), Department of Environmental Assessment, P.O. Box 1, 1755 ZG Petten, The Netherlands \\ ${ }^{\mathrm{c}}$ Wageningen University, Department of Soil Quality, P.O. Box 47, 6700 AA Wageningen, The Netherlands
}

\section{A R T I C L E I N F O}

\section{Article history:}

Received 16 May 2012

Accepted 8 November 2012

Available online 11 December 2012

\section{Keywords:}

Bottom ash

Waste incineration

Carbon speciation

Loss on ignition

TG-MS

\begin{abstract}
A B S T R A C T
The focus of this study was to identify the main compounds affecting the weight changes of bottom ash (BA) in conventional loss on ignition (LOI) tests and to obtain a better understanding of the individual processes in heterogeneous (waste) materials such as BA. Evaluations were performed on BA samples from a refuse derived fuel incineration (RDF-I) plant and a hospital waste incineration (HW-I) plant using thermogravimetric analysis and subsequent mass spectrometry (TG-MS) analysis of the gaseous thermal decomposition products. Results of TG-MS analysis on RDF-I BA indicated that the LOI measured at $550{ }^{\circ} \mathrm{C}$ was due to moisture evaporation and dehydration of $\mathrm{Ca}(\mathrm{OH})_{2}$ and hydrocalumite. Results for the HW-I BA showed that LOI at $550{ }^{\circ} \mathrm{C}$ was predominantly related to the elemental carbon (EC) content of the sample. Decomposition of $\mathrm{CaCO}_{3}$ around $700{ }^{\circ} \mathrm{C}$ was identified in both materials. In addition, we have identified reaction mechanisms that underestimate the $\mathrm{EC}$ and overestimate the $\mathrm{CaCO}_{3} \mathrm{Contents}$ of the HW-I BA during TG-MS analyses. These types of artefacts are expected to occur also when conventional LOI methods are adopted, in particular for materials that contain $\mathrm{CaO} / \mathrm{Ca}(\mathrm{OH})_{2}$ in combination with EC and/or organic carbon, such as e.g. municipal solid waste incineration (MSWI) bottom and fly ashes. We suggest that the same mechanisms that we have found (i.e. in situ carbonation) can also occur during combustion of the waste in the incinerator (between 450 and $650^{\circ} \mathrm{C}$ ) demonstrating that the presence of carbonate in bottom ash is not necessarily indicative for weathering. These results may also give direction to further optimization of waste incineration technologies with regard to stimulating in situ carbonation during incineration and subsequent potential improvement of the leaching behavior of bottom ash.
\end{abstract}

(C) 2012 Elsevier Ltd. All rights reserved.

\section{Introduction}

Loss on ignition (LOI) is one of the most adopted methods to estimate the amount of residual unburned organic carbon of the bottom ash (BA) generated during incineration of waste materials such as (presorted) municipal solid waste (MSW), industrial waste or biomass and, hence, is also generally considered as a quality control parameter of the effectiveness of the combustion process from which the BA originated. According to the current Italian legislation regulating waste thermal treatment (Leg. Decree 133, 2005), for example, one of the landfill acceptance requirements for waste incineration BA is that LOI values are equal or lower than $5 \%$ by weight.

In general, LOI refers to the mass loss of a sample after it is heated under an air or oxygen atmosphere for a certain period of time. So far, many LOI standard procedures have been developed

\footnotetext{
* Corresponding author. Tel.: +31 22456 4768; fax: +31 224568407.

E-mail address: vanzomeren@ecn.nl (A.van Zomeren).
}

each one characterized by a specific heating temperature and testing time depending on the type of analyzed material and its field of application. If a solid residue such as MSW incineration (MSWI) BA is analyzed to determine its unburned carbon content in relation to landfill disposal or reuse in e.g. concrete, a commonly accepted LOI method determines its weight loss at $550{ }^{\circ} \mathrm{C}$ for $2 \mathrm{~h}$. Therefore, high LOI values have been associated with a poor effectiveness of the combustion process from which the BA are originated (e.g. Chandler et al., 1997; Izquierdo et al., 2002). With regard to the evaluation of the organic carbon content of coal fly ash (FA) to be reused in cement production, LOI has been referred to the mass losses of samples heated to temperatures between 750 and $950{ }^{\circ} \mathrm{C}$ (Payá et al., 1998; Fan and Brown, 2001; Zhang et al., 2012).

A critical evaluation of the suitability of using LOI as a proxy for the organic carbon content of a combustion residue is particularly important because the residual organic carbon provides not only an indication of the efficiency of the combustion process, but is also an important parameter when evaluating reuse options for BA, e.g. as a material for concrete production. Furthermore, the 
study of van Zomeren and Comans (2004) indicated that only specific organic carbon species (i.e. humic substances) in the BA matrix may contribute to the leaching of dissolved organic carbon (DOC) and associated contaminants. Hence, detailed information about the different carbon species contained in BA is needed for assessing the environmental risk related to its reuse in specific application scenarios.

There is evidence that different kind of incineration residues contain (residual) organic carbon (OC) and elemental carbon (EC) species, identified using a combination of thermogravimetric (TG) and mass spectrometry (MS) analyses (Priester et al., 1996; Rubli et al., 2000; Ferrari et al., 2002; van Zomeren and Comans, 2009).

On the basis of TG analyses, it was also found that the dehydration of portlandite $\left(\mathrm{Ca}(\mathrm{OH})_{2}\right)$ and the decomposition of carbonates and/or volatile organic compounds may significantly overestimate the unburned OC content of fly ash (FA) measured adopting conventional LOI methods, as shown by Brown and Dykstra (1995) and Fan and Brown (2001).

Van Zomeren and Comans (2009) observed a large contribution from EC to the LOI results obtained for MSWI BA samples using a combination of different carbon-specific analytical techniques. The results demonstrated that only $25 \%$ of the LOI consisted of organic carbon. The authors concluded that LOI is not a sufficiently discriminative parameter for quantifying the unburned organic carbon content of BA, which proved to be overestimated on the basis of LOI analysis compared to other methods.

On the other hand, Vandenberghe et al. (2010) showed that oxidation of iron minerals in coal BA and FA samples led to a weight gain at temperatures of about $960^{\circ} \mathrm{C}$. This weight gain may partially compensate the weight loss due to the burning of the residual organic carbon (combustion at around $350^{\circ} \mathrm{C}$ ) of the sample. Thus, LOI when defined at this temperature range can possibly underestimate the remaining organic content of ash materials.

In the present study, several analytical techniques, including thermogravimetric and mass spectrometry (TG-MS) analysis were applied in order to assess the content of specific phases (i.e. hydrated compounds and inorganic, elemental and organic carbon) in BA samples originating from a refuse derived fuel (RDF) and from a hospital waste (HW) incinerators (see Section 2.1 for further description of the incineration facilities). RDF is specifically produced by sorting, size and weight based separation and shredding of commingled MSW, mainly consisting of high calorific waste fractions like paper and cardboard, plastics, textiles and rubber. Therefore, this type of feedstock material is characterized by a relatively constant size distribution and composition, leading to quite stable operating conditions of the waste thermal treatment process. On the other hand, the HW originated from medical, veterinary and/ or medical research waste, typically containing different types of infectious and toxic substances for which incineration at high temperature is required by European guidelines. Owing to the differences in composition of the feed waste and the type of incineration technology adopted by the two plants, the resulting BA were quite different in compositions and environmental behavior, as evidenced in a previous study (Rocca et al., 2009). However, the LOI values determined for the two materials were quite significant and higher than those generally reported for waste incineration BA (e.g. Chandler et al., 1997). The aim of this study was, hence, to gain insight on the main reactions and organic or inorganic species that contribute to the high LOI values ( $>5 \mathrm{wt} . \%$ in most samples) that were measured at temperatures of 550 and $1000{ }^{\circ} \mathrm{C}$ for both types of BA. Up to now, only few studies have focused on the characterization of the physical, chemical and environmental properties of these special types of BA (e.g. Kougemitrou et al., 2011; Rocca et al., 2012) and, furthermore, to our knowledge there is no comprehensive study regarding the thermal analysis and the carbon speciation of these types of waste materials.
Specifically, in order to identify and quantify the phases responsible of the LOI values measured for each type of BA, several analytical techniques were employed. First, the LOI values were compared to the overall weight losses resulting for the two types of BA samples in relation to controlled temperature variations by TG analysis. TG-MS analysis was performed to identify the major processes (e.g. water desorption, dehydration of hydrated phases, carbonate decomposition and mineral oxidation) contributing to the weight losses for each type of BA at different temperature intervals. MS analysis of the gaseous products that were released during the heating of the samples allowed us also to discriminate between the main carbon species contained in each type of BA. In addition, from the results of TG-MS analysis performed on BA samples mixed with different amounts of $\mathrm{Ca}(\mathrm{OH})_{2}$, the reactions that can take place during thermal analysis of specific materials and may affect the results of LOI or TG analysis were also identified.

\section{Materials and methods}

\subsection{Bottom ash sampling and preparation}

Approximately $100 \mathrm{~kg}$ of freshly quenched BA was sampled from two thermal treatment plants: a refuse derived fuel incineration (RDF-I) plant with a grate combustion chamber operating at temperatures between 850 and $1000{ }^{\circ} \mathrm{C}$ and a hospital waste incineration (HW-I) plant equipped with a rotary kiln combustion chamber operating at $1000-1200^{\circ} \mathrm{C}$. Both samples were homogenized by quartering and oven-dried at $60^{\circ} \mathrm{C}$. Next, both materials were sieved to produce two size classes that were separately analyzed: a coarse fraction $(0.425-12 \mathrm{~mm})$ and a fine fraction $(<0.425 \mathrm{~mm})$ which accounted for, respectively, about $90 \%$ and $10 \%$ by weight of both BA types. Experiments were performed on both the coarse and fine size fractions of the RDF-I and HW-I BA samples prior to and after 6 months of natural weathering. The weathering treatment was carried out in the laboratory by contacting the samples with air at controlled temperature and humidity and at atmospheric pressure. Detailed characterization analyses of these BA samples in terms of elemental composition, mineralogy and leaching behavior are reported in previous studies (Rocca et al., 2009, 2011, 2012).

\subsection{Loss on ignition (LOI) test methods}

Two types of LOI standard methods were employed in this study. The first method was performed according to UNI EN 15169 (2007). In this procedure the weight loss was determined after heating the samples at $550^{\circ} \mathrm{C}$ for $2 \mathrm{~h}$ (LOI 550). The second LOI method was performed in accordance with the ASTM C25 procedure (2011) by heating the samples first at $400^{\circ} \mathrm{C}$ for $30 \mathrm{~min}$, then, at $1000{ }^{\circ} \mathrm{C}$ for $20 \mathrm{~min}$ and recording the overall weight loss (LOI 1000). Tests were performed with about $5 \mathrm{~g}$ of BA placed in a ceramic crucible and heated in a muffle furnace according to one of the above cited standard procedures. After heating, the samples were placed in a desiccator for about $30 \mathrm{~min}$ before weighing. LOI was calculated as the relative weight difference between the initial and the heated sample. The difference between LOI 1000 and LOI 550 was assumed to be essentially related to the amount of carbonate phases contained in the BA samples and was hence employed to calculate the inorganic carbon content of the two types of slag. All measurements were carried out in triplicate.

\subsection{Thermogravimetric and mass spectrometry (TG-MS) analysis}

The TG-MS analysis was performed with a Mettler-Toledo TG system coupled with a Quadrupole mass-spectrometer (Pfeiffer, 
Table 1

Temperature programs applied for the RDF-I BA and the HW-I BA samples during the TG-MS analysis.

\begin{tabular}{lll}
\hline Step & Temperature range $\left({ }^{\circ} \mathrm{C}\right)$ & Isothermal time $(\mathrm{min})$ \\
\hline RDF-I BA & & \\
1 & 25 & 15 \\
2 & $25-100$ & - \\
3 & 100 & 15 \\
4 & $100-350$ & - \\
5 & 350 & 15 \\
6 & $350-1100$ & - \\
$H W-I B A$ & & \\
1 & 25 & - \\
2 & $25-100$ & 15 \\
3 & 100 & - \\
4 & $100-550$ & 15 \\
5 & 550 & - \\
6 & $550-1100$ & \\
\hline
\end{tabular}

Thermostar). About $20 \mathrm{mg}$ of BA were heated from 25 to $1100{ }^{\circ} \mathrm{C}$ under an oxygen atmosphere at a heating rate of $40^{\circ} \mathrm{C} / \mathrm{min}$. A specific temperature program was applied for each BA type in order to obtain a good separation of the individual reactions occurring at different temperatures (Table 1). Indeed, preliminary TG-MS experiments indicated that isothermal equilibration time steps of $15 \mathrm{~min}$ at the temperatures of 350 and $550{ }^{\circ} \mathrm{C}$ were needed to clearly identify the weight losses and associated gaseous products derived from the complete thermal decomposition of hydrated compounds or (organic/inorganic) carbon species present in the two types of BA. The weight loss of the samples was recorded by the TG microbalance, while the MS was used to monitor the $\mathrm{CO}_{2}$ and $\mathrm{H}_{2} \mathrm{O}$ simultaneously released from the samples. All measurements were carried out in triplicate.

\subsection{Carbonate analysis methods}

Besides LOI and TG-MS analysis, the carbonate content of the BA samples was analyzed also applying other traditionally adopted techniques, i.e.: total inorganic carbon (TIC) content and calcimetry analysis. The former was performed employing a Shimadzu TOC analyzer (V-CPH model) coupled with a solid sample module (SSM-5000A). About $100 \mathrm{mg}$ of BA were weighted and the TIC was determined after $\mathrm{H}_{3} \mathrm{PO}_{4}$ addition at $200{ }^{\circ} \mathrm{C}$ for carbonate decomposition. The released $\mathrm{CO}_{2}$ was subsequently quantified using a non-dispersive infrared detector.

In addition, the amount of carbonate in the BA samples was also measured using a Dietrich-Früling calcimeter. This analysis involved acidification $(\mathrm{HCl})$ of the sample and subsequent measurement of the total evolved gas volume. Tests were performed with about $1 \mathrm{~g}$ of material that was put into contact with $10 \mathrm{ml}$ of $(11.4 \mathrm{M}) \mathrm{HCl}$ in a glass bottle. All measurements were carried out in triplicate.

\section{Results and discussion}

\subsection{Comparison of overall weight losses measured by LOI and TG} analyses

The results of the cumulative weight losses determined by the two LOI standard methods for the different coarse and fine fractions of the fresh and aged BA samples showed that the LOI 550 values measured for the HW-I BA (from $9.6 \%$ to $23 \%$ on a dry weight basis) were generally higher compared to those obtained for the RDF-I BA (from 3\% to $8.4 \%$ on a dry weight basis), indicating a higher content of volatile compounds with low decomposition temperatures in the HW-I BA samples. On the other hand, the

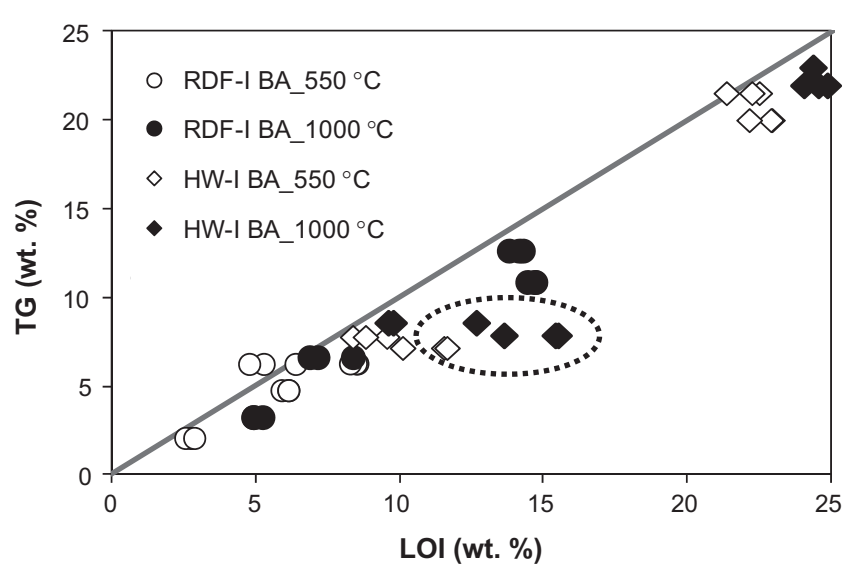

Fig. 1. Comparison of the weight loss (wt.\%) of the RDF-I BA and HW-I BA samples at $550{ }^{\circ} \mathrm{C}$ and $1000^{\circ} \mathrm{C}$ obtained by the LOI standard methods and TG analysis (up to $1100^{\circ} \mathrm{C}$, see Table 1 ). The dotted line indicates the samples exhibiting maximum deviation values between the LOI and TG results.

LOI 1000 values obtained for specific RDF-I and HW-I BA samples were quite similar for the two types of BA (from $8 \%$ to $16 \%$ on a dry weight basis) as a possible result of the significant content of carbonate phases and/or volatile compounds with high decomposition temperatures in the RDF-I samples. The detailed description of the LOI analysis results obtained for the different RDF-I and HW-I BA samples is provided in the previous study (Rocca et al., 2009). In addition, the results of the carbonates content of the two types of BA as determined by LOI analysis are described in the Section 3.3.

Fig. 1 compares the results of the two applied LOI methods (LOI 550 and LOI 1000) to the weight losses determined by TG analysis (total weight loss up to $1100^{\circ} \mathrm{C}$, following the temperature programs reported in Table 1 ) for the two types of BA samples. The RDF-I BA samples are plotted as open $\left(550^{\circ} \mathrm{C}\right)$ and closed $\left(1000^{\circ} \mathrm{C}\right)$ dots, while the HW-I BA samples are plotted as open $\left(550^{\circ} \mathrm{C}\right)$ and closed $\left(1000^{\circ} \mathrm{C}\right)$ diamonds.

The results show that the cumulative weight loss determined by LOI and TG analysis are in reasonably good agreement $\left(550{ }^{\circ} \mathrm{C}\right.$ : slope $=0.88, R^{2}=0.95 ; 1000{ }^{\circ} \mathrm{C}$ : slope $\left.=0.83, R^{2}=0.90\right)$, although the TG results were consistently lower than the LOI results. Maximum deviation between the cumulative LOI and the TG values was found at $1000^{\circ} \mathrm{C}$ for the coarse fraction of the fresh HW-I BA sample, for which the weight loss measured by TG was 7.8 wt.\% (as reported in Table 3) whereas that determined by LOI analysis was $15.5 \mathrm{wt} . \%$ (results evidenced by the dotted line in Fig. 1). These differences might be attributed to possible oxidation of (oxidizing) metals (e.g. $\mathrm{Si}, \mathrm{Zn}$ and $\mathrm{Cu}$ ) or iron-minerals (e.g. hematite, $\mathrm{Fe}_{2} \mathrm{O}_{3}$; ferrous and silicon oxides, $\mathrm{Fe}_{2} \mathrm{SiO}_{4}$ ) during TG analysis, since the use of pure oxygen in the TG experiments is likely to establish stronger oxidizing conditions than during the LOI analysis for which air is used. The results of the previous study on this BA sample corroborates the hypothesized mechanism since the coarse fractions of the ash proved to be enriched in oxidizing metals compared to the fine ones (results shown in Rocca et al., 2009).

\section{2. $T G-M S$ analysis}

3.2.1. Quantification of the different weight losses determined for the two types of bottom ash at specific temperature intervals

In Fig. 2, examples of the TG-MS results obtained for the coarse fraction of fresh RDF-I BA (graph a) and HW-I BA (graph b) are re- 
ported. Similar results, summarized in Table 2 (RDF-I BA) and Table 3 (HW-I BA), were determined for the other tested samples.

With regard to the RDF-I BA, a relatively large $\mathrm{H}_{2} \mathrm{O}$ peak was released from moisture evaporation at $100^{\circ} \mathrm{C}(0.9 \mathrm{wt}$.\%). In addition, two weight loss steps are visible at $280^{\circ} \mathrm{C}(1.2 \mathrm{wt} . \%)$ and $430^{\circ} \mathrm{C}$ ( $0.1 \mathrm{wt} . \%$ ) associated with the release of $\mathrm{H}_{2} \mathrm{O}$ as detected by the MS. These weight losses may be ascribed to the decomposition of hydrated phases, such as hydrocalumite $\left(\mathrm{Ca}_{4} \mathrm{Al}_{2} \mathrm{Cl}_{2} \mathrm{O}_{6} \cdot 10 \mathrm{H}_{2} \mathrm{O}\right)$, which shows a complete dehydration between 260 and $280^{\circ} \mathrm{C}$ (Vieille et al., 2003), and $\mathrm{Ca}(\mathrm{OH})_{2}$ which decomposes at around 400-450 ${ }^{\circ} \mathrm{C}$ (Brown and Dykstra, 1995; Payá et al., 1998). These specific two types of hydrated phases were indicated since they were both identified by X-ray diffraction (XRD) analysis in this type of BA (Rocca et al., 2012). Therefore, it is concluded that the weight loss measured for RDF-I BA at $280^{\circ} \mathrm{C}$ and $4300^{\circ} \mathrm{C}$ was most probably associated with the dehydration of hydrocalumite and $\mathrm{Ca}(\mathrm{OH})_{2}$, respectively. Additional experiments with standard addition of $\mathrm{Ca}(\mathrm{OH})_{2}$ for further confirmation of the processes controlling the weight loss of these BA samples in this temperature range are described in Section 3.2.2. The weight loss measured at around $700{ }^{\circ} \mathrm{C}(1.0 \mathrm{wt} . \%)$ in correspondence with only a $\mathrm{CO}_{2}$ peak suggested the decomposition of inorganic carbon from carbonate (a)

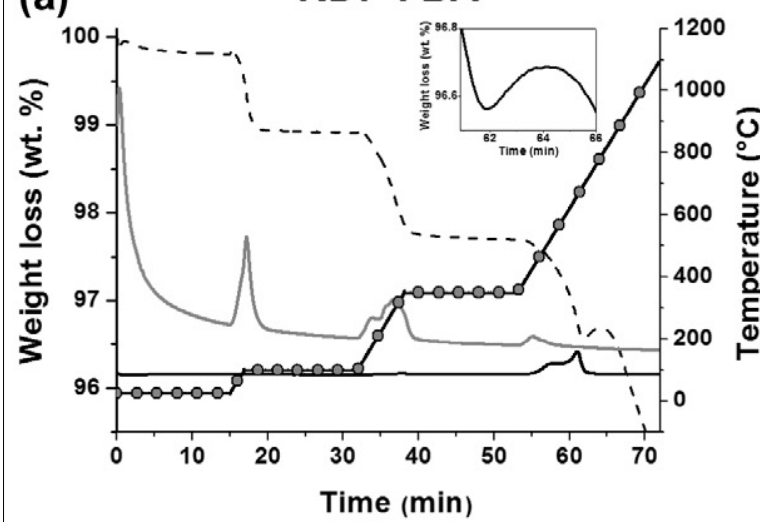

(c)

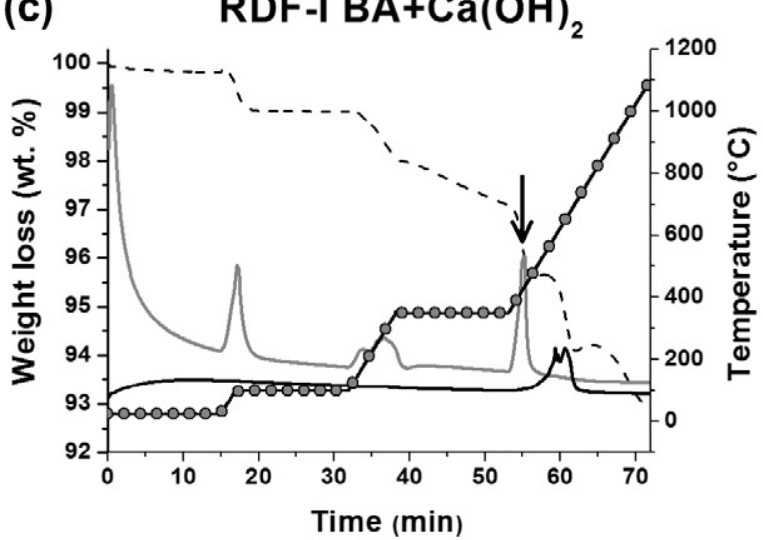

(e)

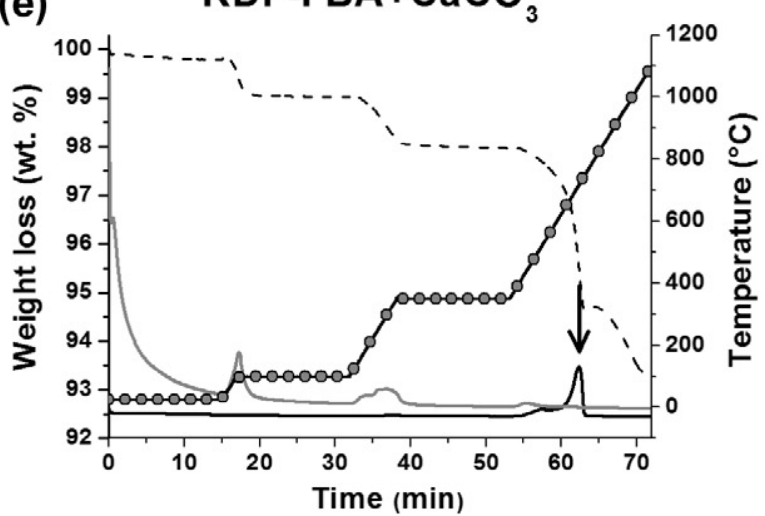

(b)

HW-I BA

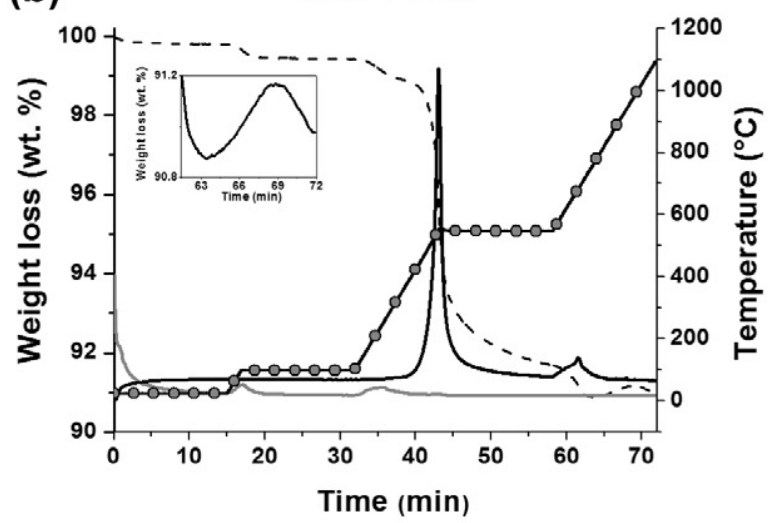

(d)

$\mathrm{HW}-\mathrm{I} \mathrm{BA}+\mathrm{Ca}(\mathrm{OH})_{2}$

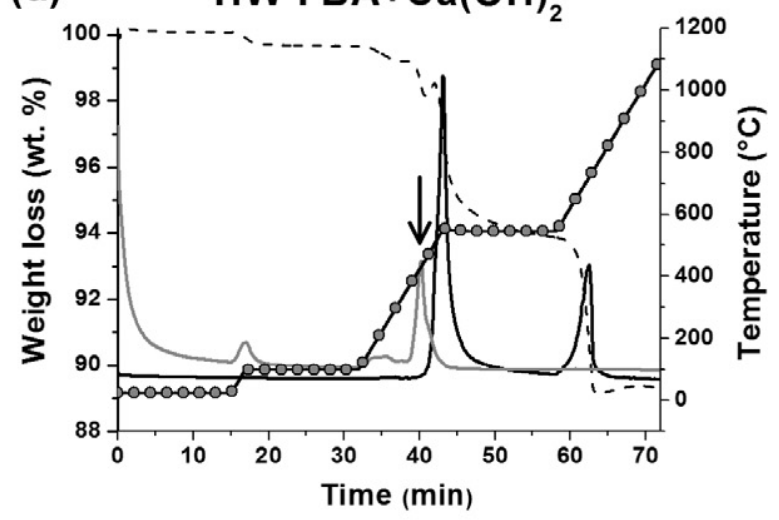

(f) $\mathrm{HW}-\mathrm{IBA}+\mathrm{CaCO}_{3}$

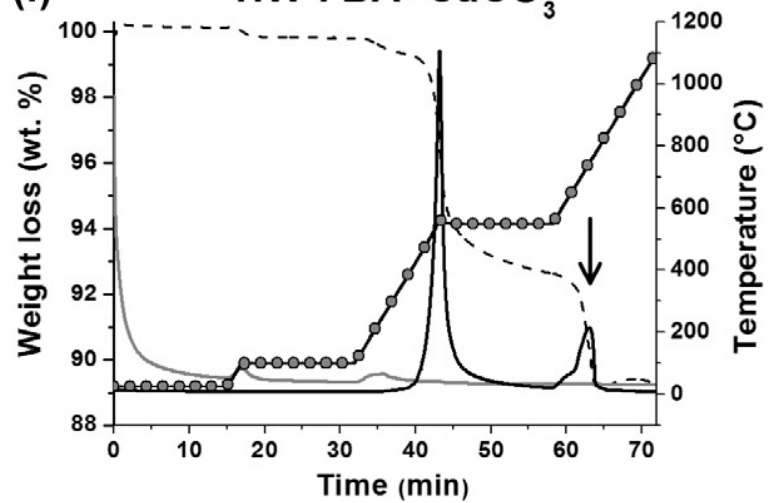

Fig. 2. Typical examples of TG-MS analysis results obtained for the coarse fraction of the fresh RDF-I BA (graph a) and the HW-I BA (graph b) samples. Results of additional TG-MS experiments with mixtures of $\mathrm{BA}$ and $\mathrm{Ca}(\mathrm{OH})_{2}$ (graphs $\mathrm{c}$ and $\mathrm{d}$ ) or $\mathrm{CaCO}_{3}$ (graphs e and $\mathrm{f}$ ) are shown in the same figure. The dashed line indicates the weight loss recorded by TG, while the line with circles represents the temperature program applied. Black and grey lines show the relative $\mathrm{MS}$ signals for evolved $\mathrm{CO}_{2}$ and $\mathrm{H}_{2} \mathrm{O}$, respectively. The insets of the graphs (a) and (b) evidence the (slight) weight gain of the samples detected from 700 to $800{ }^{\circ} \mathrm{C}$ up to $1000{ }^{\circ} \mathrm{C}$. The arrows included in the graphs indicate the increased mass losses of $\mathrm{H}_{2} \mathrm{O}$ and $\mathrm{CO}_{2}$ during additional TG-MS experiments with mixtures of $\mathrm{BA}$ and $\mathrm{Ca}(\mathrm{OH})_{2}(\mathrm{graphs})$ or $\mathrm{CaCO}_{3}$ (graphs e and f). 
Table 2

Weight loss (\% dry wt.) measured during TG analysis for all the examined RDF-I BA samples.

\begin{tabular}{|c|c|c|c|c|}
\hline \multirow[t]{2}{*}{ RDF-I BA samples } & \multicolumn{4}{|c|}{ Weight loss (wt.\%) } \\
\hline & $\begin{array}{l}100{ }^{\circ} \mathrm{C} \\
\text { (moisture) }\end{array}$ & $\begin{array}{l}280{ }^{\circ} \mathrm{C} \\
\text { (hydrated } \\
\text { phases) }\end{array}$ & $\begin{array}{l}430{ }^{\circ} \mathrm{C} \\
\left(\mathrm{Ca}(\mathrm{OH})_{2}\right)\end{array}$ & $\begin{array}{l}700{ }^{\circ} \mathrm{C} \\
\left(\mathrm{CaCO}_{3}\right)\end{array}$ \\
\hline Coarse fresh & 0.9 & 1.2 & 0.1 & 1.0 \\
\hline $\begin{array}{l}\text { Coarse } \\
\text { fresh }+\mathrm{Ca}(\mathrm{OH})_{2}\end{array}$ & 0.9 & 1.2 & 1.7 & 1.8 \\
\hline Coarse fresh $+\mathrm{CaCO}_{3}$ & 0.8 & 1.1 & 0.1 & 3.4 \\
\hline Coarse weath. & 1.8 & 2.7 & 0.3 & 1.8 \\
\hline $\begin{array}{l}\text { Coarse } \\
\quad \text { weath. }+\mathrm{Ca}(\mathrm{OH})_{2}\end{array}$ & 1.9 & 2.6 & 1.9 & 2.6 \\
\hline $\begin{array}{l}\text { Coarse } \\
\quad \text { weath. }+\mathrm{CaCO}_{3}\end{array}$ & 1.8 & 2.5 & 0.2 & 4.2 \\
\hline Fine fresh & 1.8 & 2.5 & 0.9 & 9.5 \\
\hline Fine fresh $+\mathrm{Ca}(\mathrm{OH})_{2}$ & 2.2 & 3.3 & 2.9 & 7.6 \\
\hline Fine fresh $+\mathrm{CaCO}_{3}$ & 1.7 & 2.5 & 0.9 & 12.6 \\
\hline Fine weath. & 2.6 & 3.6 & 0.6 & 4.8 \\
\hline Fine weath. $+\mathrm{Ca}(\mathrm{OH})_{2}$ & 2.1 & 3.4 & 2.4 & 6.0 \\
\hline Fine weath. $+\mathrm{CaCO}_{3}$ & 2.0 & 3.4 & 0.7 & 8.6 \\
\hline
\end{tabular}

phases $\left(\mathrm{CaCO}_{3}\right)$, in agreement with the findings of van Zomeren and Comans (2009) and Ferrari et al. (2002). This observation is also consistent with the results of the calcimetry and the XRD analyses obtained for this BA sample (Rocca et al., 2012). Additional experiments with standard additions of $\mathrm{CaCO}_{3}$ for further confirmation of the processes controlling the weight loss of these BA samples in this temperature range are described in Section 3.2.2.

The TG-MS results obtained for the HW-I BA showed a relatively large weight loss (6.2 wt.\%) of the sample at $550{ }^{\circ} \mathrm{C}$ in combination with a $\mathrm{CO}_{2}$ peak detected by the MS. Since the $\mathrm{CO}_{2}$ peak was not associated with a $\mathrm{H}_{2} \mathrm{O}$ peak, this weight loss can most probably be ascribed to the oxidation of EC, according to van Zomeren and Comans (2009). In addition, the weight loss (0.7 wt.\%) measured at about $700^{\circ} \mathrm{C}$, for which only a $\mathrm{CO}_{2}$ peak was detected by the MS was, similarly to the other type of $\mathrm{BA}$, ascribed to the presence of $\mathrm{CaCO}_{3}$ in this type of $\mathrm{BA}$, which was confirmed also by calcimetry and XRD analyses, see Rocca et al. (2009). Finally, only small amounts of water were found to be released from this type of BA at $100^{\circ} \mathrm{C}$ (moisture content) and at temperatures between 160 and $240^{\circ} \mathrm{C}$ (crystal water desorption or hydrated phases decomposition, according to Brown and Dykstra, 1995).

Furthermore, the insets of the graphs (a) and (b) in Fig. 2 shows that a small weight gain was observed in both types of ashes, from $700-800^{\circ} \mathrm{C}$ up to $1000^{\circ} \mathrm{C}$. This weight gain might be related to the oxidation of metals and/or iron-bearing minerals occurring in the ash materials as suggested by Vandenberghe et al. (2010). This observation is consistent with the presence of hematite $\left(\mathrm{Fe}_{2} \mathrm{O}_{3}\right)$ but also of iron oxide ( $\mathrm{FeO}$ ) especially in the coarse fractions of both types of BA, as detected by XRD (Rocca et al., 2009, 2012). These results also corroborate our explanation of the lower TG values compared to those of LOI, discussed in Section 3.1.

3.2.2. Identification of chemical processes as a function of temperature Subsequently, in order to further identify the origin of the $\mathrm{H}_{2} \mathrm{O}$ and $\mathrm{CO}_{2}$ peaks that were primarily released at different combustion temperatures from the two BA samples, additional TG-MS experiments with mixtures of $\mathrm{BA}$ and about $2 \mathrm{mg}$ of portlandite $\left(\mathrm{Ca}(\mathrm{OH})_{2}\right)$ or $1 \mathrm{mg}$ of calcium carbonate $\left(\mathrm{CaCO}_{3}\right)$ were performed; the amounts of the two additives were calculated such that the expected MS peaks were doubled in area. Fig. 2 shows the TG-MS results for the RDF-I BA (graphs $\mathrm{c}$ and e) and the HW-I BA (graphs d and f) when $\mathrm{Ca}(\mathrm{OH})_{2}$ or, alternatively, $\mathrm{CaCO}_{3}$ were added to the samples.

The addition of $\mathrm{Ca}(\mathrm{OH})_{2}$ to the RDF-I BA (graph c and Table 2) resulted in an increased weight loss and associated $\mathrm{H}_{2} \mathrm{O}$ peak at $430{ }^{\circ} \mathrm{C}$ as compared to the initial samples. These results confirmed the decomposition of $\mathrm{Ca}(\mathrm{OH})_{2}$ at $430{ }^{\circ} \mathrm{C}$ in these samples. The same results were obtained with the addition of $\mathrm{Ca}(\mathrm{OH})_{2}$ to the $\mathrm{HW}$-I BA samples (graph $\mathrm{d}$ and Table 3), although there was no $\mathrm{Ca}(\mathrm{OH})_{2}$ present in the original HW-I BA samples (i.e. no observed weight loss at $\left.430^{\circ} \mathrm{C}\right)$.

Fig. 2 (graph c and d) and Tables 2 and 3 also show that for both types of BA the addition of $\mathrm{Ca}(\mathrm{OH})_{2}$ caused an increased weight loss at $700{ }^{\circ} \mathrm{C}$ and a corresponding higher $\mathrm{CO}_{2}$ peak compared to the original samples, indicating an increased inorganic carbon content. Preliminary TG-MS experiments of the $\mathrm{Ca}(\mathrm{OH})_{2}$ standard sample used for these tests allowed to verify that it contained some carbonate $\left( \pm 5 \%\right.$ weight loss of $\mathrm{CaCO}_{3}$ was found in the pure $\mathrm{Ca}(\mathrm{OH})_{2}$ ) probably owing to partial carbonation during storage in the laboratory. Hence, the increased weight losses in the samples of up to $1 \%$ at $700{ }^{\circ} \mathrm{C}$ after $\mathrm{Ca}(\mathrm{OH})_{2}$ addition can be related to the presence of some $\mathrm{CaCO}_{3}$ in the $\mathrm{Ca}(\mathrm{OH})_{2}$ standard. These observations explain the increased carbonate content of the RDF-I BA (see Table 2), but not that of the HW-I BA, since the weight loss was significantly higher than $1 \%$ in this case (from 0.7 to 5.2 wt.\%).

Furthermore, the addition of $\mathrm{Ca}(\mathrm{OH})_{2}$ to the HW-I BA also showed a reduction in the weight loss at $550{ }^{\circ} \mathrm{C}$ (from 6.2 to 4.7 wt.\%) and corresponding $\mathrm{CO}_{2}$ peak that was related to the $\mathrm{EC}$ content of the sample. A possible mechanism that can explain these results is provided and discussed in Section 3.2.3.

On the other hand, the addition of $\mathrm{CaCO}_{3}$ to both BA types resulted in an increased weight loss at $700^{\circ} \mathrm{C}$ (Fig. 2, graphs (e) and (f) and Table 2 and 3 ) in combination with the formation of only $\mathrm{CO}_{2}$, compared to the initial samples. Thus, these results con-

Table 3

Weight loss (\% dry wt.) measured during TG analysis for all the examined HW-I BA samples.

\begin{tabular}{|c|c|c|c|c|c|}
\hline \multirow[t]{2}{*}{ HW-I BA samples } & \multicolumn{5}{|c|}{ Weight loss (wt.\%) } \\
\hline & $\begin{array}{l}100^{\circ} \mathrm{C} \\
\text { (moisture) }\end{array}$ & $\begin{array}{l}160-240^{\circ} \mathrm{C} \\
\text { (crystal water/hydrated phases) }\end{array}$ & $\begin{array}{l}430{ }^{\circ} \mathrm{C} \\
\left(\mathrm{Ca}(\mathrm{OH})_{2}\right)\end{array}$ & $\begin{array}{l}550^{\circ} \mathrm{C} \\
(\mathrm{EC})\end{array}$ & $\begin{array}{l}700{ }^{\circ} \mathrm{C} \\
\left(\mathrm{CaCO}_{3}\right)\end{array}$ \\
\hline Coarse fresh & 0.3 & 0.6 & - & 6.2 & 0.7 \\
\hline Coarse fresh $+\mathrm{Ca}(\mathrm{OH})_{2}$ & 0.4 & 0.5 & 1.1 & 4.7 & 5.2 \\
\hline Coarse fresh $+\mathrm{CaCO}_{3}$ & 0.3 & 0.4 & - & 6.3 & 3.6 \\
\hline Coarse weath. & 0.3 & 0.3 & - & 7.4 & 0.8 \\
\hline Coarse weath. $+\mathrm{Ca}(\mathrm{OH})_{2}$ & 0.3 & 0.3 & 1.7 & 4.7 & 4.7 \\
\hline Coarse weath. $+\mathrm{CaCO}_{3}$ & 0.2 & 0.3 & - & 6.7 & 3.4 \\
\hline Fine fresh & 0.9 & 0.3 & - & 17.6 & 1.9 \\
\hline Fine fresh $+\mathrm{Ca}(\mathrm{OH})_{2}$ & 0.9 & 0.7 & - & 14.1 & 8.5 \\
\hline Fine fresh $+\mathrm{CaCO}_{3}$ & 0.8 & 0.6 & - & 17.2 & 5.0 \\
\hline Fine weath. & 0.9 & 0.3 & - & 20.2 & 1.3 \\
\hline Fine weath. $+\mathrm{Ca}(\mathrm{OH})_{2}$ & 0.8 & 0.5 & - & 16.2 & 7.6 \\
\hline Fine weath. $+\mathrm{CaCO}_{3}$ & 0.7 & 0.5 & - & 19.0 & 5.3 \\
\hline
\end{tabular}


firm the presence and decomposition of $\mathrm{CaCO}_{3}$ at $700{ }^{\circ} \mathrm{C}$ in both bottom ash types.

\subsubsection{Reaction mechanisms occurring in bottom ash during thermal analyses}

We propose that the results presented in Fig. 2 (and Tables 2 and 3) can be explained by the following chain of reactions occurring during the TG-MS experiment. At $430{ }^{\circ} \mathrm{C}$, dehydration of $\mathrm{Ca}(\mathrm{OH})_{2}$ takes place according to Eq. (1). Next, the newly formed $\mathrm{CaO}$ reacted with (part of the) $\mathrm{CO}_{2}$ that was released from combustion of EC at $550{ }^{\circ} \mathrm{C}$ to form $\mathrm{CaCO}_{3}$ following a so called gas-solid carbonation reaction (Eq. (2)). It has been found for air pollution control residues that this reaction can occur at operating temperatures above $350{ }^{\circ} \mathrm{C}$, even for short (below $1 \mathrm{~min}$ ) contact times (Prigiobbe et al., 2009). Finally, the newly formed $\mathrm{CaCO}_{3}$ subsequently decomposed at $700{ }^{\circ} \mathrm{C}$ releasing the $\mathrm{CO}_{2}$ that originated from the oxidation of EC (Eq. (3)).

$\mathrm{Ca}(\mathrm{OH})_{2}(\mathrm{~s}) \rightarrow \mathrm{CaO}(\mathrm{s})+\mathrm{H}_{2} \mathrm{O}(\mathrm{g})$

$\mathrm{CaO}(\mathrm{s})+\mathrm{CO}_{2}(\mathrm{~g}) \rightarrow \mathrm{CaCO}_{3}(\mathrm{~s})$

$\mathrm{CaCO}_{3}(\mathrm{~s}) \rightarrow \mathrm{CaO}(\mathrm{s})+\mathrm{CO}_{2}(\mathrm{~g})$

The hypothesized mechanisms taking place during the TG-MS analyses with mixtures of $\mathrm{HW}$-I BA and $\mathrm{Ca}(\mathrm{OH})_{2}$ were found for all the samples (see Table 3 ), with the highest effects measured for the fine fraction of the fresh BA (EC decrease: from 17.6 to 14.1 wt.\% and $\mathrm{CaCO}_{3}$ increase: from 1.9 to 8.5 wt.\%). In addition, from the TG-MS results presented in Table 3 it can be noted that the weight loss due to the dehydration of $\mathrm{Ca}(\mathrm{OH})_{2}$ at $430{ }^{\circ} \mathrm{C}$ was not observed for the fine fractions of the HW-I BA when mixtures of these (fresh/weathered) samples and $\mathrm{Ca}(\mathrm{OH})_{2}$ were analyzed. The expected decrease in $\mathrm{EC}$ and increase in $\mathrm{CaCO}_{3}$ are clear for these samples, suggesting that the considerably high weight loss at $550{ }^{\circ} \mathrm{C}$ (about $18-20 \mathrm{wt} . \%$ ) due to the oxidation of EC probably masked the weight loss associated to the dehydration of $\mathrm{Ca}(\mathrm{OH})_{2}$.

As already mentioned, the TG-MS results for RDF-I BA (see Table 2) after the addition of $\mathrm{Ca}(\mathrm{OH})_{2}$ did not reveal the same effect on the increase of the $\mathrm{CaCO}_{3}$ weight loss that was observed for the HW-I BA samples. These results confirm that the RDF-I BA did not contain (unburned) carbon species that decompose at $550^{\circ} \mathrm{C}$ leading to a relevant $\mathrm{CO}_{2}$ production. When humic acid was added to the samples in preliminary experiments, both $\mathrm{CO}_{2}$ and $\mathrm{H}_{2} \mathrm{O}$ peaks appeared in the temperature range of about $300-400{ }^{\circ} \mathrm{C}$, where these peaks were absent in the original results. Furthermore, the results are in good agreement with those derived from the analysis of the Total Organic Carbon (TOC) content of the RDF-I BA, which appeared to be formed of only $0.35 \%$ wt. of unburned organic matter (Rocca et al., 2012). As such, the results of this study suggest that the relatively constant size distribution and composition of the RDF feedstock in the incineration plant possibly contributed to the high efficiency of the combustion system, resulting in a negligible content of the residual organic carbon in the produced BA. On the other hand, the TG-MS results for HW-I BA imply that a pyrolytic-like process may take place in the rotary kiln combustion system due to an oxygen-deficient atmosphere that limits the complete combustion of the HW feedstock. Consequently, the BA originating from such a thermal treatment process results in a carbonaceous solid residue that is mainly constituted of elemental black carbon with decomposition temperature of $550{ }^{\circ} \mathrm{C}$ that was clearly identified by TG-MS. With regard to these results, it must be pointed out that the elemental carbon content of the HW-I BA was adequately approximated by the TOC value of the sample, which accounted for 8-20 wt.\% (results not shown) depending on the size fractions of the analyzed material, but did not contribute to the production of the DOC and hence to an enhanced release of metals such as $\mathrm{Cu}$, as indicated by the leaching results that were obtained in a previous study on the same HW-I BA sample (Rocca et al., 2011). These findings confirmed those obtained by van Zomeren and Comans (2009).

\subsubsection{Quantification of the reaction products determined during thermal analyses}

In order to further investigate the observed decrease in EC and increase in $\mathrm{CaCO}_{3}$, TG-MS experiments were also carried out with the coarse and fine fractions of the fresh HW-I BA samples and addition of different amounts of the $\mathrm{Ca}(\mathrm{OH})_{2}$ standard sample. As shown in Fig. 3, the samples exhibited an increased weight loss of $\mathrm{H}_{2} \mathrm{O}$ (graphs a and d) in combination with a decreased weight loss of EC (graphs b and e) and increased weight loss of $\mathrm{CaCO}_{3}$ (graphs $\mathrm{c}$ and $\mathrm{f}$ ) compared to the initial samples, as an effect of the increasing addition of $\mathrm{Ca}(\mathrm{OH})_{2}$. From Fig. 3 it can also be seen that the measured mass losses of $\mathrm{H}_{2} \mathrm{O}$ (from dehydration of $\mathrm{Ca}(\mathrm{OH})_{2}$, graphs a and d) and $\mathrm{CO}_{2}$ (from decomposition of $\mathrm{CaCO}_{3}$ graphs $\mathrm{c}$ and $\mathrm{f}$ ) were always lower than the theoretical maximum values calculated based on the amounts of $\mathrm{Ca}(\mathrm{OH})_{2}$ that were added to the samples, according to Eqs. (1)-(3). This observation indicates that only a fraction of the added $\mathrm{Ca}(\mathrm{OH})_{2}$ is converted to $\mathrm{CaCO}_{3}$. This effect is particularly noticeable in Fig. 3 graphs (b) and (e) (related to decomposition of EC) which show that the theoretically calculated weight gain at high $\mathrm{Ca}(\mathrm{OH})_{2}$ additions (according to Eqs. (1) and (2)) was not observed.

Moreover, a linear correlation was observed between the measured decreases in EC and increases in $\mathrm{CaCO}_{3}$ both for the coarse and fine fractions of $\mathrm{BA}$, as an effect of the different amounts of $\mathrm{Ca}(\mathrm{OH})_{2}$ added to the samples (slope $=-0.34, R^{2}=0.98$ for the coarse sample; slope $=-0.38, R^{2}=0.97$ for the fine sample). This observation further corroborates the hypothesized chain of reactions represented by Eqs. (1)-(3).

Given the results of the additional TG-MS experiments with mixture of the BA samples and increasing amounts of $\mathrm{Ca}(\mathrm{OH})_{2}$, it can also be deduced that the conversion of free lime $(\mathrm{CaO})$ (originated from dehydration of $\mathrm{Ca}(\mathrm{OH})_{2}$ ) to $\mathrm{CaCO}_{3}$ ranged from $40 \%$ to $100 \%$. In particular, the highest conversion values were determined for the BA samples exhibiting the lowest additional amounts of $\mathrm{Ca}(\mathrm{OH})_{2}$, i.e. 1 or $2 \mathrm{mg}$. As such, the results suggest that the reaction time might not be sufficient for converting the total amount of $\mathrm{CaO}$ to $\mathrm{CaCO}_{3}$ when the highest amount of $\mathrm{Ca}(\mathrm{OH})_{2}$, i.e. 4 or $8 \mathrm{mg}$ were added to the samples during the TG-MS analyses. However, experiments with pure $\mathrm{Ca}(\mathrm{OH})_{2}$ indicated that the decomposition was complete within the time frame of the experiment. For this reason, it cannot be excluded that other, yet unknown, reactions might take place during decomposition of $\mathrm{Ca}(\mathrm{OH})_{2}$ at around $430^{\circ} \mathrm{C}$ (such as hydration of other phases).

\subsection{Comparison of the carbonate content of bottom ash determined by different methods}

The TG-MS results presented in Tables 2 and 3 indicate that the $\mathrm{CaCO}_{3}$ content of both types of BA were significantly higher in the finer particle size fractions. This effect was noteworthy in particular for the RDF-I BA (1.0 wt.\% for the coarse fraction and $9.5 \mathrm{wt} . \%$ for the fine fraction of the fresh $\mathrm{BA}$ ) in comparison to that observed for the HW-I BA samples $(0.7 \mathrm{wt} . \%$ for the coarse fraction and $1.8 \mathrm{wt} . \%$ for the fine fraction of the fresh BA). These results are consistent with those reported in previous studies on different size fractions of BA (e.g. Chimenos et al., 2003; Baciocchi et al., 2010; Onori et al., 2011). In general, the same trend was found when comparing the individual results of the LOI, TG, MS, TIC and calcimetry analyses for both types of BA. However, for the same BA sample, the $\mathrm{CaCO}_{3}$ values obtained applying the different methods 

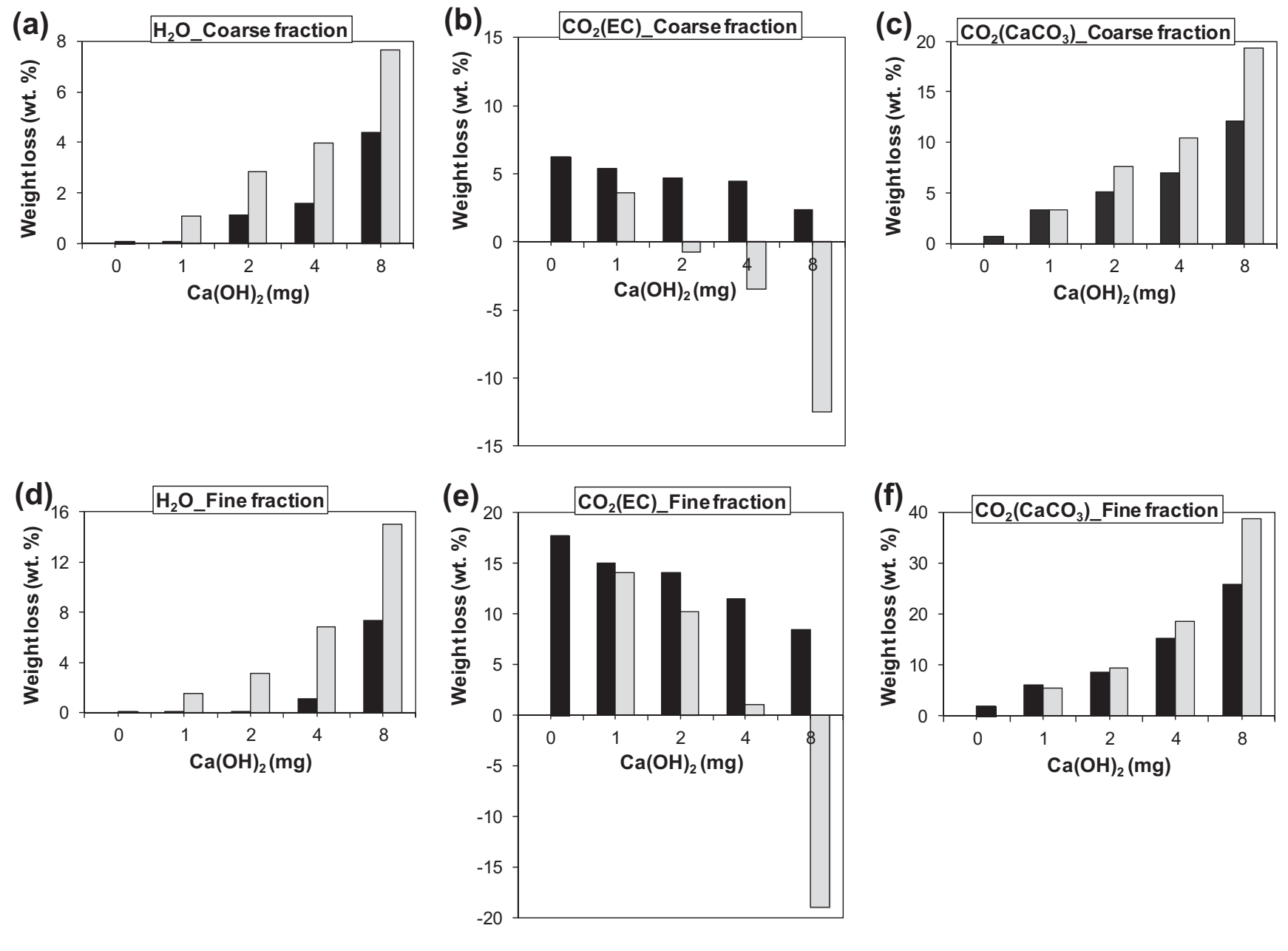

Measured

Fig. 3. Measured and calculated weight losses (wt.\%) determined by the TG-MS experiments with mixtures of the coarse (graph a, b and c) and fine (graph d, e and f) fractions of the HW-I BA samples and increasing amounts of $\mathrm{Ca}(\mathrm{OH})_{2}$ (i.e. 1, 2, 4 and $8 \mathrm{mg}$ ). The TG-MS results obtained for the initial BA samples (i.e. 0 mg of $\mathrm{Ca}(\mathrm{OH})_{2}$ ) were included in the graphs for comparison.

appeared to vary quite significantly. Results are reported in Fig. 4, in which MS value indicates the $\mathrm{CaCO}_{3}$ content calculated by integration of the peak areas for evolved $\mathrm{CO}_{2}$ at $700{ }^{\circ} \mathrm{C}$ measured by MS analysis.

With regard to the RDF-I BA (graph a), the results from LOI, TG, MS and TIC were in reasonably good agreement with each other, mainly for the coarse fraction of the fresh/weathered samples. For the fine fractions of the same type of BA, instead, TIC results proved to be higher in comparison with those obtained by TG and MS analyses.

For the HW-I BA, the results in Fig. 4 (graph b) shows that TG, MS and TIC methods led to similar $\mathrm{CaCO}_{3}$ concentrations for the coarse fractions of the sample, while LOI appeared to consistently overestimate the carbonate content for the coarse fraction of the fresh sample. On the other hand, also for the fine fractions of this type of BA, the results from TIC measurements were 2 times higher in comparison with the values determined applying the other methods.

These results suggest that the TIC method (heating of the sample at $200{ }^{\circ} \mathrm{C}$ after the addition of $\mathrm{H}_{3} \mathrm{PO}_{4}$ ) may affect the measurement accuracy of $\mathrm{CaCO}_{3}$ in these ash materials as it might account for additional $\mathrm{CO}_{2}$ quantities originating from oxidation of (a small part of) EC or decomposition of further minerals other than carbonates contained in BA. The identification of such kind of processes in these materials is needed in future research.
In addition, Fig. 4 shows that the $\mathrm{CaCO}_{3}$ content as measured by calcimetry analysis was about 2 times higher in comparison with the results obtained by the other methods for most samples of both types of BA (e.g. the coarse fraction of the fresh/weathered RDF-I $\mathrm{BA}$ and the fine fraction of the fresh/weathered HW-I BA). Calcimetry analyses is based on the estimation of the total gas volume evolved after acidification of the sample. The relatively large overestimation of the $\mathrm{CaCO}_{3}$ content might be related to the release of gaseous products other than the $\mathrm{CO}_{2}$ released from the decomposition of $\mathrm{CaCO}_{3}$. It is likely that hydrogen gas and/or $\mathrm{H}_{2} \mathrm{~S}$ were also released from the samples after contact with water and thus have contributed to the measured gas volume in the calcimeter. Hydrogen sulfide was organoleptically detected in eluates at low $\mathrm{pH}$, while the formation of hydrogen gas is known to occur in MSWI bottom ash (e.g. Chandler et al., 1997) and can be substantial (around $50 \mathrm{ml}$ per $500 \mathrm{~g}$ of BA, unpublished results).

In addition, Fig. 4 shows that the $\mathrm{CaCO}_{3}$ concentrations determined by TG analysis were only slightly lower than those derived by LOI, apart from the coarse sample of the fresh HW-I BA. Thus, from these results we can exclude that the oxidation of iron-bearing minerals occurring at $700-1000{ }^{\circ} \mathrm{C}$ (as detected in the TG-MS thermograms, see graphs (a) and (b) in Fig. 2) has substantially influenced the carbonate measurements of both the BA types. Given the findings of this study, it should be acknowledged that during the quantification of $\mathrm{CaCO}_{3}$ in heterogeneous materials, such as 

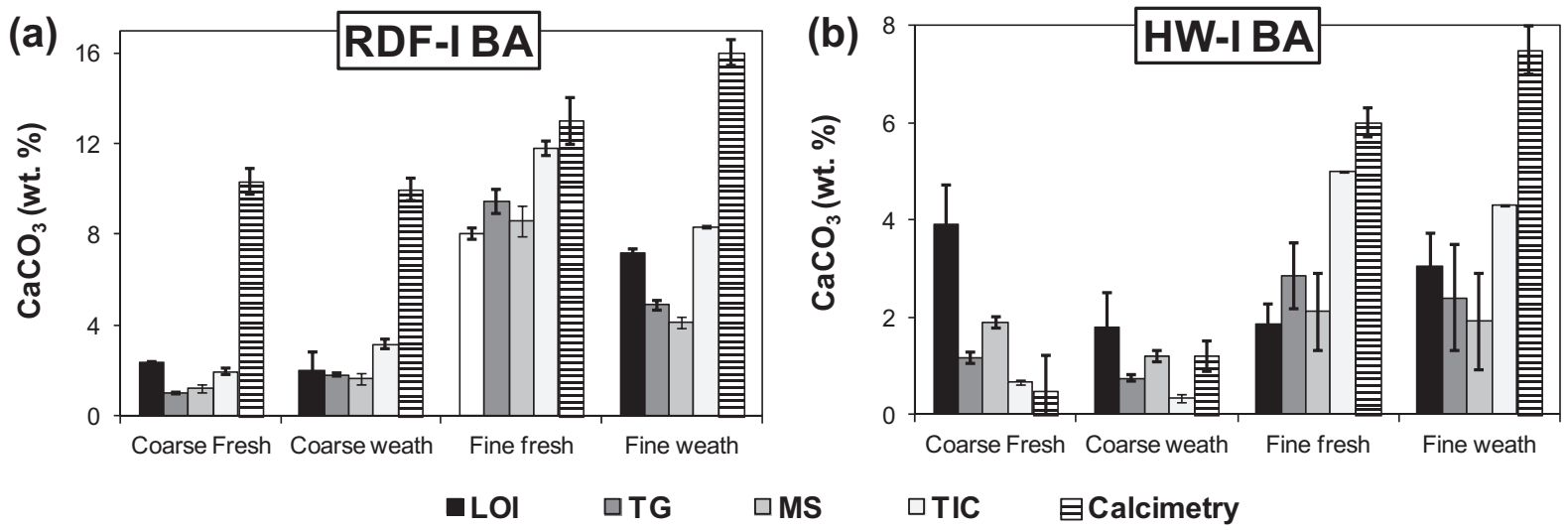

Fig. 4. Carbonate content $\left(\mathrm{CaCO}_{3}\right.$, wt.\%) in the RDF-I BA (graph a) and the HW-I BA (graph b) samples as determined by LOI (LOI 1000-LOI 550), TG, MS, TIC and calcimetry analysis. The error bars indicate the standard deviation calculated based on the triplicate measurements of each $\mathrm{CaCO}_{3}$ analysis method.

BA by each of the applied methods, other phases present in the BA matrix can contribute to the different measurement principles (weight loss, gas volume or $\mathrm{CO}_{2}$ release).

\section{Conclusions}

In the present study, bottom ash (BA) samples from two different incineration plants treating refuse derived fuel (RDF-I) and hospital waste (HW-I) were analyzed by thermogravimetric and mass spectrometry (TG-MS) analysis. The aim of this study was to identify the main compounds affecting the weight changes of BA samples determined by conventional loss on ignition (LOI) tests and to obtain a better understanding of the individual processes that take place during laboratory characterization of the carbon species in heterogeneous waste materials such as BA, by combining different analytical techniques.

The TG-MS experiments performed on RDF-I BA indicated that the LOI measured at $550{ }^{\circ} \mathrm{C}$ was mainly due to moisture evaporation and dehydration of hydrated phases. We found that hydrocalumite and $\mathrm{Ca}(\mathrm{OH})_{2}$ are most probably the phases that decompose in RDF-I BA at temperatures below $550^{\circ} \mathrm{C}$ and determine the LOI values. Both phases were identified by XRD and the decomposition of $\mathrm{Ca}(\mathrm{OH})_{2}$ was also confirmed by standard addition experiments. Furthermore, the LOI measured at $1000^{\circ} \mathrm{C}$ for this type of BA accounted for the decomposition of $\mathrm{CaCO}_{3}$ as was also confirmed by standard addition experiments. TG-MS results obtained for the HW-I BA showed that the total LOI at $550{ }^{\circ} \mathrm{C}$ mostly resulted from the decomposition of elemental carbon contained in this material. The results thus indicate that no organic carbon (OC) species could be detected in either of the examined types of materials. The results of this investigation are, hence, important for a correct interpretation of LOI measurements for waste incineration residues.

Furthermore, the TG-MS results obtained with mixtures of BA and $\mathrm{Ca}(\mathrm{OH})_{2}$ have revealed a number of processes that take place during thermal analysis (LOI and TG-MS measurements) of these materials and influence the assignment of observed results to specific carbon species. The results of this study, hence, imply that TGMS analysis and conventional LOI measurements can overestimate the carbonate content and underestimate the EC content of a combustion residue, as was clearly demonstrated for the HW-I BA. We have identified the reaction mechanisms that influence the determination of the $\mathrm{LOI}$ in general and of the $\mathrm{EC}$ and $\mathrm{CaCO}_{3}$ contents in particular. In fact, the results showed that the $\mathrm{CO}_{2}$ released from the combustion of EC (and possibly OC) is partly reacting directly with the (newly formed) $\mathrm{CaO}$ to produce $\mathrm{CaCO}_{3}$. This reaction causes an underestimation of EC because the production of $\mathrm{CaCO}_{3}$ causes a weight gain of the sample. The determination of (originally present) $\mathrm{CaCO}_{3}$ is subsequently overestimated due the $\mathrm{CaCO}_{3}$ that is newly formed during the thermal analysis. Similar phenomena are expected to occur also for other materials that contain $\mathrm{CaO} /$ $\mathrm{Ca}(\mathrm{OH})_{2}$ in combination with $\mathrm{EC} / \mathrm{OC}$, e.g. MSW incineration bottom and fly ashes. In addition, given the findings of this study, it should be realized that in the quantification of $\mathrm{CaCO}_{3}$ in heterogeneous materials, such as BA by different analytical methods, i.e. LOI, TG, MS, TIC and calcimetry other phases present in BA matrix can contribute to the measurement principles of each of the applied method (weight loss, gas volume or $\mathrm{CO}_{2}$ release).

Hence, the results of the present study may also have implications when considering the $\mathrm{CaCO}_{3}$ formation in BA. Several authors indicate that carbonates usually form as a result of several interrelated alteration processes, e.g. hydrolysis, dissolution, precipitation and carbonation which start immediately after the production of the bottom ash (e.g. Meima and Comans, 1997; Speiser et al., 2000; Polettini and Pomi, 2004). In general, it is believed that the presence and concentration of $\mathrm{CaCO}_{3}$ in $\mathrm{BA}$ samples indicates the stage of weathering of the material. It is likely that the same reactions that we observed to operate in TG-MS analysis do also occur during combustion of the waste in the incinerator. Carbonate can then be formed when the BA reaches a temperature comprised between 450 and $650{ }^{\circ} \mathrm{C}$. This finding would also explain the considerable carbonate content that has been found in unquenched and freshly quenched incineration ashes (Meima and Comans, 1997), demonstrating that the presence of carbonate in bottom ash is not necessarily indicative for weathering. As such, the carbonation process that is known to exert significant effects on the leaching behavior of bottom ash starts already during incineration. Therefore, these results may also give direction to further optimization of waste incineration technologies with regard to stimulating in situ carbonation and subsequent potential improvement of the leaching behavior of the bottom ash. The feasibility and practical considerations applying this concept have to be tested in future experiments possibly also utilizing $\left(\mathrm{CO}_{2}\right.$ enriched) recycled gas flows from the incinerator.

\section{Acknowledgements}

We thank Petra Bonouvrie for her assistance with the TG-MS experiments. Remco Koper is thanked for the LOI and TIC measurements on the samples. This work was partly funded by the Dutch Ministry of Infrastructure and Environment as part of the environmental research program of ECN. 


\section{References}

ASTM Standard C25, 2011. Standard Test Methods for Chemical Analysis of Limestone, Quicklime, and Hydrated Lime. ASTM International, West Conshohocken, PA. doi: 10.1520/C0025-11.

Baciocchi, R., Costa, G., Lategano, E., Marini, C., Polettini, A., Pomi, R., Postorino, P., Rocca, S., 2010. Accelerated carbonation of different size fractions of bottom ash from RDF incineration. Waste Management 30, 1310-1317.

Brown, R.C., Dykstra, J., 1995. Systematic errors in the use of loss-on-ignition to measure unburned carbon in fly ash. Fuel 74 (4), 570-574.

Chandler, A.J., Eighmy, T.T., Hartlen, J., Hjelmar, O., Kosson, D.S., Sawell, S.E., van der Sloot, H.A., Vehlow, J., 1997. Municipal solid waste incinerator residues. Studies in Environmental Science 67. Elsevier Science B.V., The Netherlands.

Chimenos, J.M., Fèrnandez, A.I., Miralles, L., Segarra, M., Espiell, F., 2003. Short-term natural weathering of MSWI bottom ash as a function of particle size. Waste Management 23, 887-895.

Fan, M., Brown, R.C., 2001. Comparison of the loss on ignition and thermogravimetric analysis techniques in measuring unburned carbon in coal fly ash. Energy \& Fuels 15, 1414-1417.

Ferrari, S., Belevi, H., Baccini, P., 2002. Chemical speciation of carbon in municipal solid waste incinerator residues. Waste Management 22, 303-314

Italian Committee for Standardization (UNI), 2007. EN 15169: 2007. Characterization of waste - determination of loss on ignition in waste, sludge and sediments. UNI, Milan.

Izquierdo, M., Lopez-Soler, A., Vasquez, E., Barra, M., Querol, X., 2002. Characterisation of bottom ash from municipal solid waste incineration in Catalonia. Journal of Chemical Technology and Biotechnology 77, 576-583.

Kougemitrou, I., Godelitsas, A., Tsabaris, C., Stathopoulos, V., Papandreou, A., Gamaletsos, P., Economou, G., Papadopoulos, D., 2011. Characterisation and management of ash produced in the hospital waste incinerator of Athens. Greece Journal of Hazardous Materials 187, 421-432.

Legislative Decree No 133/2005. Attuazione della direttiva 2000/76/CE, in materia di incenerimento dei rifiuti. Suppl. Ord. G.U. n. 22, as amended by Legislative Decree 11/05/2005 n. 133 (In Italian).

Meima, J.A., Comans, R.N.J., 1997. Geochemical modeling of weathering reactions in municipal solid waste incinerator bottom ash. Environmental Science and Technology 31, 1269-1276.

Onori, R., Polettini, A., Pomi, R., 2011. Mechanical properties and leaching modeling of activated incinerator bottom ash in Portland cement blends. Waste Management 31, 298-310.

Payá, J., Monzó, J., Borrachero, M.V., Perris, E., Amahjour, F., 1998. Thermogravimetric methods for determining carbon content in fly ashes. Cement and Concrete Research 28, 675-686.
Polettini, A., Pomi, R., 2004. The leaching behavior of incinerator bottom ash as affected by accelerated ageing. Journal of Hazardous Materials B113, 209-215.

Priester, T., Köster, R., Eberle, S.H., 1996. Charakterisierung kohlenstoffhaltiger Bestandteile in Hausmüllverbrennungsschlacken unter besonderer Berücksichtigung organischer Stoffe. Müll und Abfall 28, 387-398.

Prigiobbe, V., Polettini, A., Baciocchi, R., 2009. Gas-solid carbonation kinetics of Air Pollution Control residues for $\mathrm{CO}_{2}$ storage. Chemical Engineering Journal 148, 270-278.

Rocca, S., Lategano, E., Costa, G., Galeotti, L., Lombardi, F., 2009. The reuse potential of waste incineration bottom ash: a comparative experimental study. In: Proceedings Sardinia 2009, Twelfth International Waste Management and Landfill Symposium, 5-9 October, S. Margherita di Pula, Cagliari (Italy).

Rocca, S., van Zomeren, A., Costa, G., Dijkstra, J.J., Comans, R.N.J., Lombardi, F., 2011. Leaching properties of hospital waste incineration bottom ash in relation to disposal or reuse options. In: Proceedings Sardinia 2011, Thirteenth International Waste Management and Landfill Symposium, 3-7 October, S. Margherita di Pula, Cagliari (Italy).

Rocca, S., van Zomeren, A., Costa, G., Dijkstra, J.J., Comans, R.N.J., Lombardi, F., 2012. Characterisation of major component leaching and buffering capacity of RDF incineration and gasification bottom ash in relation to reuse or disposal scenarios. Waste Management 32, 759-768.

Rubli, S., Medilanski, E., Belevi, H., 2000. Characterization of total organic carbon in solid residues provides insight into sludge incineration processes. Environmental Science and Technology 2000 (34), 1772-1777.

Speiser, C., Baumann, T., Niessner, R., 2000. Morphological and chemical characterization of calcium-hydrate phases formed in alteration processes of deposited municipal solid waste incinerator bottom ash. Environmental Science and Technology 2000 (34), 5030-5037.

Vandenberghe, R.E., de Resende, V.G., da Costa, G.M., De Grave, E., 2010. Study of loss-on-ignition anomalies found in ashes from combustion of iron-rich coal. Fuel 89, 2405-2410.

van Zomeren, A., Comans, R.N.J., 2004. Contribution of natural organic matter to copper leaching from municipal solid waste incinerator bottom ash. Environmental Science and Technology 38, 3927-3932.

van Zomeren, A., Comans, R.N.J., 2009. Carbon speciation in municipal solid waste incinerator (MSWI) bottom ash in relation to facilitated metal leaching. Waste Management 29, 2059-2064.

Vieille, L., Rousselot, I., Leroux, F., Besse, J.P., Taviot-Guého, C., 2003. Hydrocalumite and its polymer derivatives. 1. Reversible thermal behavior of Friedel's salt: a direct observation by means of high-temperature in situ powder X-ray diffraction. Chemistry of Materials 15 (23), 4361-4368.

Zhang, L., Hou, J., Bi, X.T., Grace, J.R., Janke, T., Arato, C., 2012. Fluidization characteristics and charging behavior of fly ash in a vibro-fluidized bed. Powder Technology 215-216, 235-241. 